\title{
Relationships between faecal phytate and mineral excretion depend on dietary phytate and age
}

\author{
Jihye Kim ${ }^{1}$, Leslie R. Woodhouse ${ }^{2}$, Janet C. King ${ }^{3}$, Ross M. Welch ${ }^{4}$, Shan $\mathrm{Ji} \mathrm{Li}^{5}$, Hee Young Paik ${ }^{6}$ \\ and Hyojee Joung ${ }^{7} *$ \\ ${ }^{1}$ Department of Food and Nutrition, Daegu University, Gyeongbuk 712-714, South Korea \\ ${ }^{2}$ USDA, Western Human Nutrition Research Center, Davis, CA 95616, USA \\ ${ }^{3}$ Children's Hospital Oakland Research Institute, Oakland, CA 94609, USA \\ ${ }^{4}$ Plant, Soil, and Nutrition Laboratory, Cornell University, NY 14853-2901, USA \\ ${ }^{5}$ The School of Public Health, Jilin Medical College, Jilin, China \\ ${ }^{6}$ Department of Food and Nutrition, Seoul National University, Seoul 151-742, South Korea \\ ${ }^{7}$ Graduate School of Public Health and Institute of Health and Environment, Seoul National University, \\ Seoul 110-799, South Korea \\ (Received 7 October 2008 - Revised 28 October 2008 - Accepted 30 January 2009 - First published online 9 March 2009)
}

\begin{abstract}
We investigated the adverse effect of phytate on mineral absorption and the effect of dietary phytate and age on the relationship between faecal phytate and faecal mineral excretion. Fourteen young women (aged 19-24 years) and fourteen elderly women (64-75 years) were studied for two metabolic periods (MP). In MP1, the subjects consumed a controlled high-phytate (HP) diet for $10 \mathrm{~d}$; in MP2, they were on a low-phytate (LP) diet for $10 \mathrm{~d}$. In each period, diet samples and complete faecal samples for $5 \mathrm{~d}$ were collected to analyse phytate and mineral contents. Mineral concentrations in diet and faeces were measured by inductively coupled plasma-atomic emission spectrometry. Linear regression analysis was used to examine the associations between faecal phytate and mineral excretion. The degradation rate of dietary phytate was about $77 \%$ for young women, which was significantly lower than that of elderly women $(86 \%)(P<0.05)$. Faecal phytate excretion was positively correlated with mineral excretion ( $\mathrm{Ca}, \mathrm{P}, \mathrm{Fe}$ and $\mathrm{Zn})$ in both the HP and LP diet groups in young women $(P<0 \cdot 05)$. The linear relationship tended to be greater during the LP diet period compared with the HP diet period in young women. However, no association was found between phytate excretion and mineral excretion in elderly women. In summary, undegraded dietary phytate (10-20\%) had a negative effect on mineral absorption in young women, and the relationship between faecal phytate and mineral excretion was affected by both dietary phytate and age.
\end{abstract}

Dietary phytate: Degradation: Mineral excretion: Age

Phytate is known to have an inhibitory effect on mineral absorption by forming insoluble complexes with essential minerals, such as $\mathrm{Zn}, \mathrm{Ca}, \mathrm{Cu}$ and $\mathrm{Fe}^{(1,2)}$. Experimental data have shown the negative effects of phytate on mineral absorption in human subjects. Zn absorption averaged about $35 \%$ when young and elderly subjects were fed dephytinised diets (phytate: $\mathrm{Zn}$ molar ratio $=0$ ), but the absorption declined to about $20 \%$ when the phytate:Zn molar ratio was increased to $20^{(3)}$. In human subjects, $\mathrm{Fe}$ absorption from oat porridge with a phytate content of $107 \mu \mathrm{mol} / \mathrm{l}$ was shown to be $60 \%$, compared with only $44 \%$ absorption from oat porridge containing phytate at $432 \mu \mathrm{mol} / \mathrm{l}^{(4)}$.

It has been found that phytate is not hydrolysed by humans due to our lack of phytase activity ${ }^{(5)}$. Recently it was observed that a considerable amount of dietary phytate was degraded in the human gut $^{(6)}$. This degradation is of importance because the mineral-binding capacity decreases when the phosphate groups are removed and thus may reduce the adverse effects of phytate on mineral bioavailability. However, the effect of undegraded dietary phytate on the absorption of minerals such as $\mathrm{Ca}, \mathrm{Fe}, \mathrm{Cu}$ and $\mathrm{Zn}$ has not been elucidated yet. Therefore, it is necessary to identify the impact of undegraded dietary phytate on mineral excretion when a substantial amount of phytate degradation has occurred in the gastrointestinal (GI) tract of humans.

Concerns about the impact of dietary phytate on mineral status have been raised among certain vulnerable subpopulations, including children, pregnant women, the elderly and vegetarians $^{(3,7-11)}$. The elderly are thought to be at higher risk of mineral deficiency than younger adults due to a lower intake and/or a reduced absorption with ageing ${ }^{(12-14)}$. Some studies reported that adjustment of $\mathrm{Zn}$ absorption or homeostasis with the change of dietary phytate did not differ between young and elderly women ${ }^{(3,15)}$. On the

Abbreviations: GI, gastrointestinal; HP, high-phytate; IP5, myo-inositol 1, 3, 4, 5, 6-pentakis-phosphate; IP6, myo-inositol 1, 2, 3, 4, 5, 6-hexakis-phosphate; LP, low-phytate; MP, metabolic period.

* Corresponding author: Dr Hyojee Joung, fax +82 2745 9104, email hjjoung@snu.ac.kr 
contrary, the inhibitory effect of dietary phytate on apparent $P$ absorption was not observed in elderly women and was found to be unlikely in young women ${ }^{(6)}$. Hence, further studies of the effect of age on mineral absorption or metabolism are needed.

The objectives of the present study were to determine the effect of phytate on mineral excretion, and the effect of dietary phytate and age on the relationships between faecal phytate and mineral excretion in Korean women.

\section{Experimental methods}

\section{Subjects}

Fourteen healthy younger women (aged 19-24 years) and fourteen healthy elderly women (aged 64-75 years) were recruited for the study through word of mouth and flyers on the campus of Seoul National University (Seoul, South Korea), and in neighbouring areas. Exclusion criteria included BMI of $<17$ or $>26 \mathrm{~kg} / \mathrm{m}^{2}$, smoking, chronic use of alcohol, prescription drugs, oral contraceptives, vitamin or mineral supplements, $\mathrm{Hb}$ level of less than $105 \mathrm{~g} / \mathrm{l}$, the presence of acute disease or chronic disease such as diabetes, GI disorder, hyperlipidaemia, and a usual dietary $\mathrm{Zn}$ intake of less than $5 \mathrm{mg} / \mathrm{d}$ or greater than $15 \mathrm{mg} / \mathrm{d}$.

All subjects gave their informed consent to participate in the present study. The study protocol was reviewed and approved by the Committee on Human Research of the College of Human Ecology at Seoul National University and the Davis Office of Human Research Protection at the University of California.

\section{Study design}

The metabolic balance study was divided into two $10 \mathrm{~d}$ metabolic periods (MP) and the subjects lived in a metabolic unit during the two MP and consumed diets provided from the metabolic kitchen. Upon completion of the first MP of the high-phytate (HP) diet, subjects returned to their homes to commence a $10 \mathrm{~d}$ washout period before starting the second period of the low-phytate (LP) diet. While subjects were on their usual diet during the washout period, they were instructed to avoid HP foods so that they could adapt more easily to the LP diet of the second period. Complete faecal samples were collected for 5-6 consecutive days starting from day 5 of each MP. A $3 \mathrm{~d}$ diet record for young women and $24 \mathrm{~h}$ dietary recall for elderly women were completed before MP1 for estimating usual intakes of energy, protein, phytate and minerals as described in Kim et al. ${ }^{(15)}$. The usual intakes of nutrients were calculated by the estimated values from a nutrient database developed by the Korean Nutrition Society ${ }^{(16)}$.

\section{Diets}

A $2 \mathrm{~d}$ cycle menu, composed of common Korean foods, was used for the two controlled metabolic diets (Table 1). The HP diet was fed in MP1 (phytate:Zn molar ratios were 24 for young women and 27 for elderly women); the lowerphytate diet was fed in MP2 (phytate:Zn molar ratios were 10 for young women and 12 for elderly women). On the day 1 menu, a phytase enzyme from Aspergillus niger (5000 U/g; BASF, Mount Olive, NJ, USA) was added to the brown rice gruel served at breakfast and the soyabean curd

Table 1. Menus for the controlled diets for young women ${ }^{\star}$

\begin{tabular}{|c|c|c|c|c|}
\hline & \multicolumn{2}{|c|}{ High-phytate diet } & \multicolumn{2}{|c|}{ Low-phytate diet } \\
\hline & Day 1 & Day 2 & Day 1 & Day 2 \\
\hline \multirow[t]{6}{*}{ Breakfast } & Brown rice gruel & Ham and cheese sandwich & Brown rice gruel $†$ & Ham and cheese sandwich \\
\hline & Kimchi & Orange juice & Kimchi & Orange juice \\
\hline & Grilled seaweed & & Grilled seaweed & \\
\hline & Grilled yellow croaker & & Grilled yellow croaker & \\
\hline & Seasoned lettuce & & Seasoned lettuce & \\
\hline & Orange juice & & Orange juice & \\
\hline \multirow[t]{8}{*}{ Lunch } & Cooked brown rice & $\begin{array}{l}\text { Cooked brown rice with } \\
\text { soyabeans }\end{array}$ & Cooked rice & Cooked rice \\
\hline & Steamed egg & Kimchi & $\begin{array}{l}\text { Soyabean curd residue stew } \\
\text { (biji) } \dagger\end{array}$ & Kimchi \\
\hline & Grilled tofu with seasoning & $\begin{array}{l}\text { Soyabean paste soup with } \\
\text { Chinese cabbage }\end{array}$ & Seasoned cucumber & $\begin{array}{l}\text { Soyabean paste soup with } \\
\text { Chinese cabbage }\end{array}$ \\
\hline & Seasoned bean sprout & Braised lotus root & Seasoned squash & Braised lotus root \\
\hline & Kimchi & Pan-fried fish & Yogurt & Pan-fried fish \\
\hline & Milk & Milk & Milk & Milk \\
\hline & Banana & Apple & Tomato & Apple \\
\hline & Tomato & & & Banana \\
\hline \multirow[t]{7}{*}{ Dinner } & Cooked brown rice & Cooked brown rice & Cooked rice & Cooked rice \\
\hline & Kimchi & $\begin{array}{l}\text { Soyabean curd residue stew } \\
\text { (biji) }\end{array}$ & Kimchi & Steamed egg \\
\hline & Sea mustard soup & Seasoned cucumber & Sea mustard soup & Grilled tofu with seasoning \\
\hline & Stir-fried chicken & Seasoned squash & Stir-fried chicken & Seasoned bean sprouts \\
\hline & Potato salad & Watermelon & Potato salad & Watermelon \\
\hline & Seasoned spinach & & Seasoned spinach & Kimchi \\
\hline & Watermelon & & Watermelon & \\
\hline
\end{tabular}

${ }^{*}$ A few adjustments were made in food items for the elderly; see the Diets section of the Experimental methods.

$\dagger$ These foods were treated with phytase to reduce the phytate content. 
served for lunch to lower the phytate content of the diet during $\mathrm{MP} 2^{(17)}$. A quantity of $2 \mathrm{mg}$ phytase was added to $100 \mathrm{~g}$ brown rice and incubated at $4^{\circ} \mathrm{C}$ for $6 \mathrm{~h}$ and $4 \mathrm{mg}$ phytase was added to $100 \mathrm{~g}$ soyabean curd residue and incubated at $4^{\circ} \mathrm{C}$ for $3 \mathrm{~h}$. On day 2, white rice replaced brown rice at lunch and dinner to reduce the phytate content of the total day's diet.

Several items on the younger women's menus were substituted to accommodate the food preferences of the elderly women without changing the energy, protein, $\mathrm{Ca}, \mathrm{Fe}$ and $\mathrm{Cu}$ content of the menus or the $\mathrm{Zn}$ or phytate content. The ham and cheese sandwich was substituted with beef and vegetable gruel and grilled seaweed for elderly women at breakfast on day 2. Soya milk replaced milk for lunch on days 1 and 2 and tangerine replaced watermelon at dinner on days 1 and 2 .

All food and water provided were prepared in the metabolic kitchen during the two MP. The women either ate their meals in the metabolic kitchen or living room in the metabolic unit, or in their workplace with members of our staff. Diet samples of each meal were prepared and analysed for minerals and phytate. The energy and protein contents of the study diets were determined by the estimated values from a nutrient database developed by the Korean Nutrition Society (Table 2) ${ }^{(16,18)}$.

\section{Sample collection and analyses}

Each meal and every faecal sample were stored in polyethylene bags at $-20^{\circ} \mathrm{C}$. Stored diets and faecal samples were freezedried, homogenised using a blender, and stored in desiccators until analysis. Samples of the freeze-dried diets $(0.2-0.4 \mathrm{~g})$ and faecal samples $(0 \cdot 1-0 \cdot 2 \mathrm{~g})$ were microwave digested (MARS 5; CEM Corp., Matthews, NC, USA) with $4 \mathrm{ml}$ concentrated $\mathrm{HNO}_{3}$ (trace-metal grade; Fisher Scientific, Pittsburgh, PA, USA). Diet and faecal samples were diluted with $1 \%$ $\mathrm{HNO}_{3}$ (trace-metal grade; Fisher Scientific) before mineral analysis. Mineral content in the diet and faecal samples was determined by inductively coupled plasma-atomic emission spectrometry (Vista; Varian Inc., Walnut Creek, CA, USA). Myo-inositol 1, 3, 4, 5, 6-pentakis-phosphate (IP5) and myo-inositol 1, 2, 3, 4, 5, 6-hexakis-phosphate (IP6) forms of phytate contents were determined by the Dionex Liquid Chromatograph System (Dionex Corp., Sunnyvale, CA, USA) after phytate extraction. Phytate (IP6), IP5 and phosphate ion $\left(\mathrm{PO}_{4}^{3-}\right)$ were extracted using a modification of the procedure from Lehrfeld ${ }^{(19)}$. All measurements were done in triplicate. Further details can be found in Kim et al. ${ }^{(15)}$.

The degradation rate of dietary phytate was calculated as follows:

Degradation rate of dietary phytate $(\%)=(($ phytate intake

- faecal phytate excretion)/phytate intake) $\times 100$.

\section{Statistical analysis}

Results are expressed as mean values and standard deviations. Statistical analyses were conducted with SAS 9.1 (SAS Institute Inc., Cary, NC, USA). Differences of means between age groups were tested by $t$ tests. Main effects and interactions for diet groups and age on faecal excretion of mineral and phytate were determined using ANOVA. Associations between faecal phytate and mineral excretion were examined using linear regression analyses. The statistical tests were executed using a two-sided significance level of $5 \%$. All significant differences were defined as $P<0 \cdot 05$.

\section{Results}

The characteristics of the young and elderly women in the study are described in Table 2. Their usual intakes of energy and minerals, such as $\mathrm{Ca}, \mathrm{Cu}, \mathrm{Fe}$ and $\mathrm{Zn}$, did not differ significantly between the young and elderly women. Usual phytate intakes of the elderly women were about $67 \%$ higher than those of the younger women.

Phytate excretion did change significantly with dietary phytate and age (Tables 3 and 4). Faecal phytate excretion was significantly higher during the HP period than the LP period in young women $(P<0 \cdot 05)$. No significant differences were

Table 2. Baseline characteristics of the study participants

(Mean values, standard deviations and ranges)

\begin{tabular}{|c|c|c|c|c|c|c|}
\hline & \multicolumn{3}{|c|}{ Young women ( $n$ 14) } & \multicolumn{3}{|c|}{ Elderly women $(n 14)$} \\
\hline & Mean & SD & Range & Mean & SD & Range \\
\hline Age (years) & 23 & 2 & $19-24$ & 70 & 3 & $64-75$ \\
\hline Weight (kg) & 54 & 7 & $46-74$ & 57 & 5 & $49-68$ \\
\hline Height (cm) & 161 & 5 & $153-172$ & $157^{\star}$ & 4 & $148-162$ \\
\hline BMI $\left(\mathrm{kg} / \mathrm{m}^{2}\right)$ & 21 & 2 & $17-25$ & $23^{\star}$ & 3 & $19-28$ \\
\hline \multicolumn{7}{|l|}{ Usual dietary intakest } \\
\hline Energy $(\mathrm{MJ} / \mathrm{d})$ & 6.9 & $2 \cdot 1$ & $4 \cdot 3-12 \cdot 8$ & $7 \cdot 2$ & 2.4 & $3.9-11 \cdot 2$ \\
\hline Protein (g/d) & 59 & 19 & $33-104$ & 76 & 38 & $25-162$ \\
\hline $\mathrm{Ca}(\mathrm{mg} / \mathrm{d})$ & 538 & 215 & $224-950$ & 566 & 200 & $226-902$ \\
\hline $\mathrm{Fe}(\mathrm{mg} / \mathrm{d})$ & $12 \cdot 6$ & 6.6 & $5 \cdot 0-22 \cdot 7$ & 11.7 & $4 \cdot 1$ & $4 \cdot 2-18 \cdot 2$ \\
\hline $\mathrm{Cu}(\mathrm{mg} / \mathrm{d})$ & 0.87 & 0.29 & $0.47-1.32$ & 1.03 & 0.27 & $0.80-1.52$ \\
\hline $\mathrm{Zn}(\mathrm{mg} / \mathrm{d})$ & $7 \cdot 4$ & $2 \cdot 4$ & $3.6-12.9$ & 7.4 & $3 \cdot 2$ & $3 \cdot 6-13 \cdot 6$ \\
\hline Phytate $(\mathrm{mg} / \mathrm{d})$ & 264 & 324 & $62-1350$ & 508 & 479 & $53-2002$ \\
\hline Phytate:Zn molar ratio $\ddagger$ & 3.8 & $4 \cdot 1$ & $1.5-17 \cdot 4$ & 6.9 & $5 \cdot 6$ & $1.5-23.1$ \\
\hline
\end{tabular}

* Mean value was significantly different from that of the young women $(P<0.05 ; t$ test $)$.

$\dagger$ Values were estimated by $1 \mathrm{~d}$ dietary recall at screening interviews using a database from the Korean Nutrition Society ${ }^{(16)}$ and a previous report ${ }^{(18)}$.

$\ddagger$ Phytate: $\mathrm{Zn}$ molar ratio $=($ phytate intake/phytate molecular weight $(660)) /(\mathrm{Zn}$ intake/Zn molecular weight $(65 \cdot 4))$. 
Table 3. Nutrient intakes of phytate and minerals during the metabolic periods*

\begin{tabular}{|c|c|c|c|c|}
\hline & \multicolumn{2}{|c|}{ Young women } & \multicolumn{2}{|c|}{ Elderly women } \\
\hline & HP diet & $\overline{\text { LP diet }}$ & HP diet & $\overline{\text { LP diet }}$ \\
\hline Energy $(\mathrm{MJ} / \mathrm{d})$ & $7 \cdot 4$ & 7.4 & $7 \cdot 3$ & 7.4 \\
\hline Protein $(\mathrm{g} / \mathrm{d})$ & 77 & 76 & 74 & 75 \\
\hline $\mathrm{Ca}(\mathrm{mg} / \mathrm{d})$ & 781 & 662 & 722 & 700 \\
\hline$P(\mathrm{mg} / \mathrm{d})$ & 1468 & 1254 & 1556 & 1201 \\
\hline $\mathrm{Fe}(\mathrm{mg} / \mathrm{d})$ & 5.5 & 6.3 & 5.9 & 5.5 \\
\hline $\mathrm{Cu}(\mathrm{mg} / \mathrm{d})$ & $1 \cdot 1$ & $1 \cdot 1$ & 1.5 & 1.2 \\
\hline $\mathrm{Zn}(\mathrm{mg} / \mathrm{d})$ & 6.5 & $6 \cdot 5$ & $6 \cdot 3$ & $6 \cdot 3$ \\
\hline Phytate $(\mathrm{mg} / \mathrm{d})$ & 1584 & 681 & 1723 & 782 \\
\hline Phytate:Zn molar ratio† & 24 & 10 & 27 & 12 \\
\hline
\end{tabular}

HP, high-phytate; LP, low-phytate.

${ }^{*}$ Nutrient contents were calculated using a database from the Korean Nutrition Society ${ }^{(16)}$.

†Phytate:Zn molar ratio $=($ phytate intake/phytate molecular weight $(660)) /(\mathrm{Zn}$ intake/Zn molecular weight (65.4)).

observed in the elderly women. Degradation rates of dietary phytate in the elderly subjects were higher compared with the young women on both the HP and LP diets $(P=0.023)$, and the degradation rates were significantly higher during the HP diet period compared with the LP diet period $(P=0.002)$.

There were significant positive relationships between faecal phytate and mineral excretion in young women in both the HP diet and LP diet periods $(P<0.05$; Table 5). Faecal minerals such as $\mathrm{Ca}, \mathrm{P}, \mathrm{Fe}$ and $\mathrm{Zn}$ were excreted more according to the increase of faecal phytate excretion in young women. The relationship between faecal phytate and mineral excretion tended to be greater during the LP diet period in young women. However, no association was found between phytate excretion and mineral excretion in elderly women.

\section{Discussion}

We found a positive relationship between faecal phytate and mineral excretion $(\mathrm{Ca}, \mathrm{P}, \mathrm{Fe}, \mathrm{Zn})$ in young women. The degradation rate of dietary phytate in young women was about $80 \%$ in the present study. These results indicate that undegraded dietary phytate (IP5 + IP6), about $20 \%$, inhibited absorption of minerals such as $\mathrm{Ca}, \mathrm{Fe}$ and $\mathrm{Zn}$, although considerable amounts of dietary phytate were degraded in the GI tract of young subjects.

Several studies have reported a negative effect of phytate on mineral bioavailability in animals and human subjects. A study of rats showed that apparent absorption and retention of $\mathrm{Ca}, \mathrm{P}, \mathrm{Fe}$ and $\mathrm{Zn}$ in rats fed the phytate-free diet were significantly higher than those in rats fed either a soyabean protein diet or a casein diet for 5 weeks, but not for 2 weeks ${ }^{(20)}$. In a study of piglets, mineral absorption $(\mathrm{Ca}, \mathrm{P})$ and urinary excretion $(\mathrm{P}, \mathrm{Cu})$ were increased by the addition of the phytase enzyme $^{(21)}$. By reducing IP5 and IP6 in the diet with phytase treatment, $\mathrm{Fe}$ absorption in healthy adults increased by $78 \%{ }^{(22)}$. However, Davidsson et al. ${ }^{(23)}$ reported no significant differences in apparent absorption of $\mathrm{Ca}, \mathrm{Fe}, \mathrm{Cu}$ and $\mathrm{Zn}$ between regular and dephytinised soya formula, as based on the faecal excretion of non-absorbed isotope during $72 \mathrm{~h}$ balances in healthy infants. A direct comparison is not possible 
Table 5. Relationship between faecal phytate and mineral excretion in young and elderly women (Regression coefficients)

\begin{tabular}{|c|c|c|c|c|c|c|c|c|}
\hline & \multicolumn{4}{|c|}{ Young women } & \multicolumn{4}{|c|}{ Elderly women } \\
\hline & \multicolumn{2}{|c|}{ High-phytate } & \multicolumn{2}{|l|}{ Low-phytate } & \multicolumn{2}{|l|}{ High-phytate } & \multicolumn{2}{|l|}{ Low-phytate } \\
\hline & Regression coefficient & $P$ & Regression coefficient & $P$ & Regression coefficient & $P$ & Regression coefficient & $P$ \\
\hline $\mathrm{Ca}$ & 0.4186 & 0.0388 & 0.8656 & 0.0115 & -0.0123 & NS & -0.3703 & NS \\
\hline$P$ & 0.7536 & $<0.0091$ & 0.8283 & 0.0267 & -0.0010 & NS & -0.4028 & NS \\
\hline $\mathrm{Fe}$ & 0.0060 & 0.0672 & 0.0141 & 0.006 & 0.0010 & NS & -0.0025 & NS \\
\hline $\mathrm{Cu}$ & 0.001 & NS & 0.003 & NS & 0.000 & NS & 0.000 & NS \\
\hline $\mathrm{Zn}$ & 0.0076 & 0.0120 & 0.0101 & 0.0170 & 0.0003 & NS & -0.0051 & NS \\
\hline
\end{tabular}

because of many differences in the conditions of the studies (for example, species, age, the method of measuring mineral absorption).

Faecal mineral excretion was influenced by both dietary phytate and age of the women. The regression coefficients between faecal phytate and mineral excretion tended to be higher during the LP diet period than the HP diet period in young women (Table 5). However, it is not clear why the relationship between faecal phytate and mineral excretion was greater during the LP diet period in young women.

On the other hand, the positive relationship between faecal phytate and mineral excretion was not observed in elderly women. The lack of an inhibitory effect of phytate on mineral absorption with ageing may be due to an adaptation to HP diets occurring in the GI tract of elderly women, who are considered to have consumed high levels of phytate through their traditional Korean diet for a long time. The adaptation might lead to the higher phytate degradation rate in elderly subjects compared with younger subjects consuming HP diets. This increased rate of degradation during HP diets in elderly women would result in similar amounts of undegraded phytate between the two MP and it might change the inhibitory effect of phytate on mineral absorption. A previous study ${ }^{(6)}$ reported the possibility of adaptation to an HP diet in the human gut by showing that the increased dietary phytate intake could stimulate phytate degradation in the gut over time.

Phytate degradation may occur from three sources of phytase found in the GI tract, i.e. dietary phytase, intestinal mucosal phytase, or phytase produced by the small-intestinal microflora $^{(24)}$. Some investigators suggested the induction of mucosal phytase by dietary phytate in rats ${ }^{(25,26)}$, but intestinal mucosal phytase seems to play a minor role compared with dietary phytase for phytate hydrolysis ${ }^{(5)}$. Lopez et al. ${ }^{(25)}$ showed that the enhancement of mucosal phytase induced by dietary phytate improves intestinal $\mathrm{Ca}$ absorption in rodents, demonstrating the adaptation of the small intestine to diets rich in phytate and poor in Ca. However, a direct application of the rat results to humans may be not possible because the ability of various species of single-stomached animals to hydrolyse phytate varies. Moore \& Veum ${ }^{(27)}$ showed that rats fed a marginal-P diet can compensate for the lack of available $\mathrm{P}$ by a greater phytate degradation, suggesting an adaptation in the intestinal microflora. This adaptation may result from enhanced phytase or alkaline phosphatase synthesis by the GI microflora stimulated by a lower level of phytate in the digesta ${ }^{(27)}$. However, the role of small-intestinal microflora in phytate degradation is still disputed. On the other hand, Brune et al. ${ }^{(28)}$ observed that the inhibitory effect of phytate on Fe absorption did not differ between a group of vegetarians with a regular HP intake and a control group, suggesting no intestinal adaptation to an HP diet. The possible degree of the subjects' adaptation to HP diets is not yet clear. Thus, it is necessary to elucidate if adaptation to the long-term HP diet can occur in the human GI tract. Also, studies on the adaptation mechanism and influencing factors, such as the genetic difference of the phytase enzyme, are required.

Since the metabolic diet provided a much higher level of phytate compared with the habitual diet, the adaptation to the HP diet might cause greater inter-individual variation among subjects. A greater variation in baseline dietary intake for $\mathrm{Zn}$ and phytate among elderly women compared with younger women could affect the adaptation of elderly women to an HP diet and it might cause less impact on mineral excretion. Weaver ${ }^{(29)}$ showed that the inter-individual difference of $\mathrm{Ca}$ retention/absorption in the meals was a result of many factors, and individual absorptive efficiencies could account for a great part of the variations in absorption.

The extent of faecal mineral excretion, except for $\mathrm{P}$, was similar between the HP and LP diet periods in the present study. The impact of dietary phytate on mineral excretion was not as great as we previously thought. Our findings were in contrast to the results of other human studies ${ }^{(28,30-32)}$. The addition of $100 \mathrm{mg}$ or more phytate-P significantly decreased $\mathrm{Ca}$ retention compared with the test meals with no added phytate at day 7, suggesting the dose-dependent inhibitory effect of sodium phytate on retention of $\mathrm{Ca}$ in men ${ }^{(32)}$. The inhibitory effect of phytate on $\mathrm{Fe}$ absorption has been found to be dose dependent ${ }^{(30,33)}$. A recent study reported that the inhibitory effect of dietary phytate explained $82 \%$ of the variance in $\mathrm{Zn}$ absorption as measured by stable isotope techniques in the mathematical model of quantity of $\mathrm{Zn}$ absorbed per d as a function of dietary $\mathrm{Zn}$ and phytate ${ }^{(31)}$. The results of the present study may indicate that a considerable amount of dietary phytate might have been degraded in the stomach and small intestine since the absorption of minerals mostly occurs in the small intestine. It has been known that phytate is not hydrolysed by humans due to the lack of phytase activity ${ }^{(5)}$. However, an ileostomy human study found that dietary phytate was partly digested in the stomach and small intestine (39-76\%), but did not impair the apparent absorption of $\mathrm{Ca}$ and $\mathrm{Mg}$ from the small intestine ${ }^{(34)}$. On the other hand, Schlemmer et al. ${ }^{(35)}$ reported that the degradation of dietary phytate occurs in the colon as well as in the stomach and small intestine of pigs, irrespective of their diet. 
Therefore, further studies are needed on the extent of phytate degradation in different parts of the GI tract as well as on the influencing factors of phytate degradation, such as the age of subjects and the long-term phytate intake.

The present study has some limitations. First, no information was provided on the faecal excretion of phytate and $\mathrm{Zn}$ at baseline. Second, no correction was made for re-excreted and absorbed minerals when measuring faecal excretion. This correction may be more critical for some minerals (for example, $\mathrm{Zn}$ ) than for others (for example, Fe). Thus, endogenous faecal excretion of some minerals should be considered when exploring the effect of phytate on mineral absorption in future studies.

\section{Conclusion}

The present study shows that faecal phytate excretion is positively related to mineral excretion, and undegraded phytate (about $10-20 \%$ ) has a negative impact on mineral absorption in young women. The inhibitory effect of phytate on mineral absorption was affected by both dietary phytate and age. The impact of phytate on mineral utilisation should be examined further considering the long-term phytate intake and age of subjects in future studies. Also, both beneficial and adverse health effects of phytate need to be studied since a considerable amount of dietary phytate was degraded in the human gut.

\section{Acknowledgements}

The present study was funded by the Korea Research Foundation (KRF 2001-003-D00119). The study was conducted according to the guidelines laid down in the Declaration of Helsinki and all procedures involving human subjects were approved by the Committee on Human Research of the College of Human Ecology at Seoul National University and the Davis Office of Human Research Protection at the University of California. Written informed consent was obtained from all subjects.

J. K. contributed to the analysis and interpretation of the data, and manuscript preparation. L. R. W. and J. C. K. were involved in coordinating the study and contributed to the study design. R. M. W. was involved in data collection and analysis. S. J. L. was the data manager and was also involved in data collection. H. Y. P. was the principal investigator at the early phase of the study and was involved in the study design. H. J. was responsible for all the process of the study. All authors read and approved the final manuscript.

The authors declare that they have no competing interests.

\section{References}

1. Cheryan M (1980) Phytic acid interactions in food systems. Crit Rev Food Sci Nutr 13, 297-335.

2. Lonneral B (2002) Phytic acid-trace element ( $\mathrm{Zn}, \mathrm{Cu}, \mathrm{Mn}$ ) interactions. Int J Food Sci Technol 37, 749-758.

3. Couzy F, Kastenmayer P, Mansourian R, et al. (1993) Zinc absorption in healthy elderly humans and the effect of diet. Am J Clin Nutr 58, 690-694.

4. Larsson M, Rossander-Hulthen L, Sandstrom B, et al. (1996) Improved zinc and iron absorption from breakfast meals containing malted oats with reduced phytate content. $\mathrm{Br} J \mathrm{Nutr}$ 76, 677-688.
5. Sandberg AS \& Andersson H (1988) Effect of dietary phytase on the digestion of phytate in the stomach and small intestine of humans. J Nutr 118, 469-473.

6. Joung H, Jeun BY, Li SJ, et al. (2007) Fecal phytate excretion varies with dietary phytate and age in women. J Am Coll Nutr 26, 295-302.

7. Gibson RS, Donovan UM \& Heath AL (1997) Dietary strategies to improve the iron and zinc nutriture of young women following a vegetarian diet. Plant Foods Hum Nutr 51, 1-16.

8. Gibson RS \& Huddle JM (1998) Suboptimal zinc status in pregnant Malawian women: its association with low intakes of poorly available zinc, frequent reproductive cycling, and malaria. Am J Clin Nutr 67, 702-709.

9. Lonnerdal B (1989) Dietary factors affecting trace element absorption in infants. Acta Paediatr Scand Suppl 351, 109-113.

10. Manary MJ, Hotz C, Krebs NF, et al. (2002) Zinc homeostasis in Malawian children consuming a high-phytate, maize-based diet. Am J Clin Nutr 75, 1057-1061.

11. Mendoza C, Viteri FE, Lonnerdal B, et al. (1998) Effect of genetically modified, low-phytic acid maize on absorption of iron from tortillas. Am J Clin Nutr 68, 1123-1127.

12. August D, Janghorbani M \& Young VR (1989) Determination of zinc and copper absorption at three dietary $\mathrm{Zn}-\mathrm{Cu}$ ratios by using stable isotope methods in young adult and elderly subjects. Am J Clin Nutr 50, 1457-1463.

13. Dixon LB, Winkleby MA \& Radimer KL (2001) Dietary intakes and serum nutrients differ between adults from food-insufficient and food-sufficient families: Third National Health and Nutrition Examination Survey, 1988-1994. J Nutr 131, 1232-1246.

14. Turnlund JR, Durkin N, Costa F, et al. (1986) Stable isotope studies of zinc absorption and retention in young and elderly men. J Nutr 116, 1239-1247.

15. Kim J, Paik HY, Joung H, et al. (2007) Effect of dietary phytate on zinc homeostasis in young and elderly Korean women. $J$ Am Coll Nutr 26, 1-9.

16. Korean Nutrition Society (2000) Recommended Dietary Allowances for Koreans, 7th revision. Seoul: Korean Nutrition Society.

17. Manary MJ, Hotz C, Krebs NF, et al. (2000) Dietary phytate reduction improves zinc absorption in Malawian children recovering from tuberculosis but not in well children. $J$ Nutr 130, 2959-2964.

18. Kim J, Paik HY, Joung H, et al. (2004) Zinc supplementation reduces fractional zinc absorption in young and elderly Korean women. J Am Coll Nutr 23, 309-315.

19. Lehrfeld J (1994) HPLC separation and quantification of phytic acid and some inositol phosphates in foods: problems and solutions. J Agric Food Chem 42, 2726-2731.

20. Kamao M, Tsugawa N, Nakagawa K, et al. (2000) Absorption of calcium, magnesium, phosphorus, iron and zinc in growing male rats fed diets containing either phytate-free soybean protein or soybean protein isolate or casein. J Nutr Sci Vitaminol (Tokyo) 46, 34-41.

21. Kies AK, Gerrits WJ, Schrama JW, et al. (2005) Mineral absorption and excretion as affected by microbial phytase, and their effect on energy metabolism in young piglets. $J$ Nutr 135, 1131-1138.

22. Zhang H, Onning G, Oste R, et al. (2007) Improved iron bioavailability in an oat-based beverage: the combined effect of citric acid addition, dephytinization and iron supplementation. Eur J Nutr 46, 95-102.

23. Davidsson L, Ziegler EE, Kastenmayer P, et al. (2004) Dephytinisation of soyabean protein isolate with low native phytic acid content has limited impact on mineral and trace element absorption in healthy infants. Br J Nutr 91, 287-294.

24. Sandberg AS (2002) In vitro and in vivo degradation of phytate. In Food Phytates, pp. 139-155. Boca Raton, FL: CRC Press. 
25. Lopez HW, Leenhardt F, Coudray C, et al. (2002) Minerals and phytic acid interactions: is it a real problem for human nutrition? Int J Food Sci Technol 37, 727-739.

26. Yang WJ, Matsuda Y, Sano S, et al. (1991) Purification and characterization of phytase from rat intestinal mucosa. Biochim Biophys Acta 1075, 75-82.

27. Moore RJ \& Veum TL (1983) Adaptive increase in phytate digestibility by phosphorus-deprived rats and the relationship of intestinal phytase (EC 3.1.3.8) and alkaline phosphatase (EC 3.1.3.1) to phytate utilization. Br J Nutr 49, 145-152.

28. Brune M, Rossander L \& Hallberg L (1989) Iron absorption: no intestinal adaptation to a high-phytate diet. Am J Clin Nutr $49,542-545$.

29. Weaver CM (1992) Calcium bioavailability and its relation to osteoporosis. Proc Soc Exp Biol Med 200, 157-160.

30. Hallberg L, Brune M \& Rossander L (1989) Iron absorption in man: ascorbic acid and dose-dependent inhibition by phytate. Am J Clin Nutr 49, 140-144.
31. Miller LV, Krebs NF \& Hambidge KM (2007) A mathematical model of zinc absorption in humans as a function of dietary zinc and phytate. J Nutr 137, 135-141.

32. Fredlund $\mathrm{K}$, Isaksson $\mathrm{M}$, Rossander-Hulthen $\mathrm{L}$, et al. (2006) Absorption of zinc and retention of calcium: dosedependent inhibition by phytate. J Trace Elem Med Biol 20, $49-57$.

33. Brune M, Rossander-Hulten L, Hallberg L, et al. (1992) Iron absorption from bread in humans: inhibiting effects of cereal fiber, phytate and inositol phosphates with different numbers of phosphate groups. J Nutr 122, 442-449.

34. Sandberg AS, Hasselblad C, Hasselblad K, et al. (1982) The effect of wheat bran on the absorption of minerals in the small intestine. Br J Nutr 48, 185-191.

35. Schlemmer U, Jany KD, Berk A, et al. (2001) Degradation of phytate in the gut of pigs - pathway of gastro-intestinal inositol phosphate hydrolysis and enzymes involved. Arch Tierernahr 55, 255-280. 